CLINICAL @LERT

\title{
Should abnormal oesophageal motility in gastro-oesophageal reflux disease (GORD) influence decisions about fundoplication?
}

\author{
R C Heading
}

\begin{abstract}
Does abnormal oesophageal motility in gastro-oesophageal reflux disease affect the outcome of laparoscopic fundoplication?
\end{abstract}

fu it important to perform oesophageal function tests before surgery for gastro-oesophageal reflux disease (GORD)? For some years now, oesophageal manometry and a $\mathrm{pH}$ study have formed part of the "work up" of GORD patients being considered for fundoplication, supposedly (i) to ensure that the diagnosis of GORD is correct, (ii) to allow surgery to be "tailored" - a partial wrap fundoplication being performed in patients with especially poor oesophageal motility to minimise the risk of postoperative dysphagia, ${ }^{1-3}$ and (iii) to obtain preoperative data so that the success of treatment can be appraised from postoperative measurements in the same patient. As technology has advanced, the increasing complexity of manometry reports and 24 hour $\mathrm{pH}$ data have allowed impressively detailed documents from the oesophageal laboratory to be inserted into each patient's case notes but also raise some questions about whether all of these numbers really contribute to clinical decisions about antireflux surgery.

This work by Fibbe et al from Hamburg is the latest and best designed of several studies published in the last few years that have shown preoperative oesophageal manometry to be of no value in predicting the occurrence of dysphagia after fundoplication. ${ }^{4-6}$ Moreover, postoperative dysphagia was not reduced by using a partial wrap instead of a complete wrap in patients with preoperative evidence of impaired peristalsis. Although there is some evidence that supports the appealing concept of tailoring a patient's surgery to preoperative physiological findings, ${ }^{127}$ the results of Fibbe et al agree with a previous randomised trial that found no advantage in using preoperative manometry to guide the choice of wrap.

These observations are directly relevant to clinical practice but other findings reported by Fibbe et al offer additional food for thought and perhaps also point the way for further research. Noting that abnormal oesophageal body motility was unrelated to the presence of

Fibbe C, Layer P, Keller J, et al. Esophageal motility in reflux disease before and after fundoplication: a prospective randomized, clinical and manometric study. Gastroenterology 2001;121:5-14

Background: The role of impaired oesophageal motility, which is found in up to $50 \%$ of patients with severe gastro-oesophageal reflux disease (GORD), is unclear. Some studies have suggested that fundoplication can correct the motility disturbance and that tailoring the type of fundoplication will improve the clinical outcome.

Aims: To determine whether (i) oesophageal dysmotility is associated with severity of GORD symptoms and outcome of fundoplication and (ii) whether a complete (Nissen) or partial (Toupet) fundoplication improves oesophageal dysmotility.

Study design and setting: Randomised controlled trial in single German teaching hospital.

Methods: A total of 200 patients (median age 56 years) with GORD who had undergone an endoscopy, oesophageal manometry, and 24 hour $\mathrm{pH}$ monitoring prior to surgery were stratified according to the presence or absence of oesophageal dysmotility and then randomised to either a Nissen or Toupet laparoscopic fundoplication. Four months after operation patients were reassessed and had repeat endoscopy, manometry, and $\mathrm{pH}$ testing performed by a single observer unaware of the surgical procedure.

Results: Preoperative dysmotility was associated with more severe reflux symptoms, more frequent resistance to medical treatment (64\% v 49\%; $<<0.05)$, and a greater decrease in oesophageal sphincter pressure compared with normal motility (9.5 v $12.4 \mathrm{~mm} \mathrm{Hg} ; \mathrm{p}<0.005)$. Nevertheless, postoperatively, clinical outcomes and reflux recurrence $(21 \% \vee 14 \%)$ were similar in those with and without dysmotility. Oesophageal motility remained unchanged in $85 \%$ of patients, was normalised in 20 (10 Nissen/10 Toupet), and became abnormal in nine (eight Nissen/one Toupet).

Conclusions: Oesophageal dysmotility: (1) reflects more severe disease; (2) does not affect the postoperative outcome at four months; $(3)$ is not corrected by either type of fundoplication; (4) may develop as a result of fundoplication; and (5) requires no tailoring of surgical management.

oesophagitis or GORD duration, consistent with the concept that it is a primary phenomenon, they suggest that at least some of the changes in oesophageal motility after fundoplication are a consequence of oesophageal outflow resistance. In patients with normal motility preoperatively, dysphagia and peristaltic failure followed the Nissen procedure more often than the Toupet. However, neither preoperative dysphagia nor postoperative new onset dysphagia was consistently associated with motor abnormality in the oesophageal body, inviting the conclusion that standard manometric techniques are inadequate to detect the responsible dysfunction. This is an important message: Fibbe et al have provided unequivocal answers to the primary questions they have asked but have also demonstrated that straightforward manometry is incapable of resolving many of the questions that remain. Dysphagia in the context of GORD presumably occurs as a consequence of impaired bolus transit and we now need to spend more time studying transit than oesophageal contraction patterns alone. What of the lower sphincter/high pressure zone? An attempt to understand dysphagia in GORD, especially postoperatively, must look at the dynamics of 
lower sphincter relaxation, intrabolus pressure just above the sphincter, and transit of the bolus through it.

In taking this subject further, we must also grapple with the problem of how to assess and categorise dysphagia in a way that begins to match the sophistication of the physiological measurements we can now make. Is the dysphagia intermittent or persistent? For liquids as well as solids? Do some patients report "no dysphagia" because self imposed dietary restrictions have kept it at bay? Do others experience dysphagia mainly because of the way they eat and swallow? ${ }^{8}$ There are other uncertainties too, obviously, but there are as many inadequacies and oversimplifications in our current assessments of dysphagia as there are limitations associated with standard oesophageal manometry.

It is self evident that the diagnosis of GORD should be certain before antireflux surgery is undertaken. In patients being considered for operation, manometry and $\mathrm{pH}$ testing using currently available standard methods can contribute to confirmation of this diagnosis and will identify the rare diagnostic surprise, such as previously unrecognised achalasia or scleroderma, which may prompt a rethink about surgery. However, neither preoperative nor postoperative dysphagia in the GORD patient is being adequately explained by our current evaluations of oesophageal function. A better understanding of the mechanisms causing dysphagia is needed if we are to minimise and perhaps prevent its occurrence postoperatively.

\section{Authors' affiliations}

R C Heading, Centre for Liver and Digestive

Disorders, Royal Infirmary, Edinburgh

EH3 9YW, UK; R.Heading@ed.ac.uk

\section{REFERENCES}

1 Wetscher GJ, Glaser K, Wieschemeyer T, et al. Tailored antireflux surgery for gastro-oesophageal reflux disease: effectiveness and risk of postoperative dysphagia. World J Surg 1997;21:605-10.

2 Alexiou C, Beggs D, Salama FD, et al. A tailored surgical approach for gastro-oesophageal reflux disease: the Nottingham experience. Eur J Cardiothorac Surg 2000;17:389-95

3 Watson A. Update: Total versus partial laparoscopic fundoplication. Dig Surg 1998;15:172-80.

4 Beckingham IJ, Cariem AK, Bornman PC, et al. Oesophageal dysmotility is not associated with poor outcome after laparoscopic Nissen fundoplication. Br J Surg 1998;85:1290-3.

5 Baigrie RJ, Watson DI, Myers JC, et al. Outcome of laparoscopic Nissen fundoplication in patients with disordered preoperative peristalsis. Gut 1997;40:381-5.

6 Rydberg L, Ruth M, Abrahamsson $\mathrm{H}$, et al. Tailoring antireflux surgery: A randomized clinical trial. World J Surg 1999;23:612-18.

7 Lund RJ, Wetscher GJ, Raiser F, et al. Laparoscopic Toupet fundoplication for gastroesophageal reflux disease with poor esophageal body motility. J Gastrointest Surg 1997; 1:301-8.

8 Howard PJ, Maher L, Pryde A, et al. Esophageal motor patterns during episodes of dysphagia for solids. J Gastrointest Motil 1991;3:123-30.

\section{New GUT online submission and review system}

The Editors of GUT are pleased to inform authors and reviewers of its new online submission and review system. Bench>Press is a fully integrated electronic system which uses the internet to allow rapid and efficient submission of manuscripts, plus the entire peer review process to be conducted online.

Authors can submit their manuscript in any standard word processing software. Graphic formats acceptable are: .jpg, .tiff, .gif, and eps. Text and graphic files are automatically converted to PDF for ease of distribution and reviewing purposes. Authors are asked to approve their submission before it formally enters the reviewing process.

To access the system click on "SUBMITTING A MANUSCRIPT" on the GUT homepage: http://www.gutjnl.com/, or you can access Bench>Press directly at http://submitgut.bmijournals.com/.

We are very excited with this new development and we would encourage authors and reviewers to use the online system where possible. It really is simple to use and should be a big improvement on the current peer review process. Full instructions can be found on Bench>Press and GUT online. Please contact Natalie Davies, Project Manager, ndavies@bmigroup.com for further information.

\section{PRE-REGISTER WITH THE SYSTEM}

We would be grateful if all GUT authors and reviewers pre-registered with the system. This will give you the opportunity to update your contact and expertise data, allowing us to provide you with a more efficient service.

Instructions for registering

1. Enter http://submit-gut.bmijournals.com

2. Click on "Create a New Account" in the upper left hand side of the Bench>Press

homepage

3. Enter your email address in the space provided.

4. Choose a password for yourself and enter it in the spaces provided.

5. Complete the question of your choice to be used in the event you cannot remember your password at a later time.

6. Click on the "Save" button at the bottom of the screen.

7. Check the e-mail account you registered under. An email will be sent to you with

a verification number and URL.

8. Once you receive this verification number, click on the URL hyperlink and enter

the verification number in the relevant field. This is for security reasons and to

check that your account is not being used fraudulently.

9. Enter/amend your contact information, and update your expertise data. 